\title{
Article \\ Preparation and Study on Fretting Tribological Behavior of Composite Lubrication Structure on the Titanium Alloy Surface
}

\author{
Zhen Ma ${ }^{1,2}$, Junjie Song ${ }^{1}$, Hengzhong Fan ${ }^{1}$, Tianchang $\mathrm{Hu}^{1, *}$ and Litian $\mathrm{Hu}^{1,2, *(D)}$ \\ 1 State Key Laboratory of Solid Lubrication, Lanzhou Institute of Chemical Physics, Chinese Academy of \\ Sciences, Lanzhou 730000, China; mazhen@licp.cas.cn (Z.M.); songjunjie@licp.cas.cn (J.S.); \\ hzhfan@licp.cas.cn (H.F.) \\ 2 Center of Materials Science and Optoelectronics Engineering, University of Chinese Academy of Sciences, \\ Beijing 100049, China \\ * Correspondence: htchang@licp.cas.cn (T.H.); lthu@licp.cas.cn (L.H.)
}

check for

updates

Citation: Ma, Z.; Song, J.; Fan, H.;

$\mathrm{Hu}, \mathrm{T}$.; Hu, L. Preparation and Study on Fretting Tribological Behavior of Composite Lubrication Structure on the Titanium Alloy Surface. Coatings 2022, 12, 332. https://doi.org/ 10.3390/coatings12030332

Academic Editors: Damian Przestacki, Michal Kulka, Wensheng Li and Pier Luigi Bonora

Received: 21 December 2021

Accepted: 24 February 2022

Published: 3 March 2022

Publisher's Note: MDPI stays neutral with regard to jurisdictional claims in published maps and institutional affiliations.

Copyright: (c) 2022 by the authors. Licensee MDPI, Basel, Switzerland. This article is an open access article distributed under the terms and conditions of the Creative Commons Attribution (CC BY) license (https:// creativecommons.org/licenses/by/ $4.0 /)$.

\begin{abstract}
As an excellent light metal material, titanium alloy has an important application in high technology equipment. In this study, the composite lubrication structure was prepared on the titanium alloy surface by combining the surface texture, thermal oxidation layer, and polytetrafluoroethylene (PTFE)-based lubricating coating. The effect of texture parameters and thermal oxidation layer on the fretting wear behavior of the composite lubrication structure was evaluated under a load of $50 \mathrm{~N}$. The results showed that the PTFE-based lubricating coating on the textured surface showed excellent friction-reduction and anti-wear effect compared with the coating on the single smooth surface and thermal oxidation surface. The introduction of a thermal oxidation layer on the textured surface further improved the fretting wear life of lubrication coating. The friction coefficient and wear rate can be as low as 0.242 and $2.3 \times 10^{-5} \mathrm{~mm}^{3} \cdot \mathrm{N}^{-1} \mathrm{~m}^{-1}$, respectively, under dry fretting contact conditions. Compared with the untextured surface, the longevity of the composite lubrication structure is extended by more than $90 \%$.
\end{abstract}

Keywords: titanium alloy; surface texture; thermal oxidation; fretting friction

\section{Introduction}

The vast development of light metal materials has been gradually applied to various fields. Titanium alloy has a series of important properties such as low density, corrosion resistance, high strength to weight ratio, and so on. Therefore, it is widely used in aerospace, marine, medical and other fields [1-3]. However, its poor wear resistance, unstable and high friction coefficient, low thermal conductivity and bearing capacity limit its further application to a great extent [4,5]. Especially in the aviation field, when titanium alloy is used as structural components in turbine blades and disks, compressor blades and disks, and other systems, the contact surface often causes fatigue damage due to fretting wear, resulting in fracture failure of materials [6,7]. Therefore, it is necessary to modify the surface of titanium alloy to enhance its fretting wear resistance under severe conditions.

Generally, enhancing the wear resistance of titanium alloy mainly includes the following ways: laser cladding [8], ion implantation [9], micro-arc oxidation [10], and so on. However, under severe conditions such as fretting, the coating or modified coating shows very limited wear life. Therefore, it is essential to use composite surface treatment technology to further enhance the fretting tribological properties of titanium alloy [11]. As a new surface engineering technology, laser surface texture provides a new way for the preparation of composite wear resistant structures on the surface of titanium alloy.

Laser surface texture (LST) is a key technology that can fabricate micro-scale structures on the surface of materials. Previous studies have shown that the friction and wear of the materials can be effectively reduced by laser surface texture under different conditions [12-14]. Li et al. [15] studied the effect of dimple textures on tribological properties 
of TA2 titanium under simulated lunar soil particles in dry sliding contact. The results showed that the textured surface exhibited a better tribological performance under the small particle condition. The dimple density had an obvious effect on both the frictionreduction and anti-wear performance, and the dimple depth had almost no effect on the tribological behavior. Conradi et al. [16] investigated the influence of three kinds of textures on friction and wear of Ti6Al4V surface. The lines and grid lines showed better frictional characteristics in Hank's solution. The dimples and low-density line textures showed the best wear resistance under the dry-lubrication conditions. However, the low wear resistance of the titanium alloy surface still greatly restricts the improvement of its friction performance. On this basis, to further improve the wear life of textured titanium alloy surface under fretting friction, a wear resistant layer with high hardness needs to be formed on the bearing surface.

Current research has proved that thermal oxidation (TO) is a simple, efficient, and pollution-free way to raise the bearing capacity and wear resistance of titanium alloy [17] Through thermal oxidation surface treatment technology, a thick hard oxide layer can be formed on the surface of titanium alloy, which plays an effective protective role [18]. Dalili [19] et al. studied the effect of thermal oxidation on the friction properties of TC4/TiC composites. The results show that the thermal oxidation treatment can significantly reduce the wear of materials, especially under high load conditions. It is considered that the thermal oxidation layer of high hardness can effectively improve the bearing capacity and reduce plastic deformation. As well demonstrated, PTFE solid lubricant is a common self-lubricating material, which has the advantages of outstanding chemical stability and low friction coefficient. The bonded solid lubricating coatings based on PTFE have excellent adhesion, anti-corrosion, and anti-fretting wear performance [20,21]. At present, it is widely used in the automotive, aerospace, and manufacturing fields. Furthermore, one of the advantages of surface texture in enhancing tribological properties is that it acts as a storage pool of lubricating medium to supply lubricant in the friction process [22]. Therefore, if the PTFE solid lubricant is introduced into the patterned structure of the thermal oxidation textured surface of titanium alloy, it is expected to form a self-lubricating composite wear resistant structure, to further enhance the anti-friction and wear resistant effect and effectively prolong the wear life of titanium alloy.

Based on the above background, this study attempts to prepare the composite lubrication structure on the surface of titanium alloy by combining the laser surface texture, thermal oxidation layer and bonded PTFE-based lubricating coating. The effects of the texture parameters, thermal oxidation layer, and PTFE coating on the tribological properties of titanium alloy surface are analyzed, and the friction and wear mechanisms under fretting conditions are explored.

\section{Experimental Procedure}

The commercial TC4 alloy (Beijing Hui Sheng New Material Technology Co., Ltd., Beijing, China) was used as substrate with a hardness of $350 \pm 15 \mathrm{HV}_{200 \mathrm{~g}}$. The chemical composition of TC4 is shown in Table 1 . The samples were pre-ground successively with 1000, 1200, 1500 and 2000 mesh $\mathrm{SiC}$ sandpapers, and then were polished with polishing cloth. The surface roughness was about 0.03 to $0.05 \mu \mathrm{m}(\mathrm{Ra})$. The surface textures were prepared by using the UV laser machining system (wavelength: $355 \mathrm{~nm}$ ), and the laser parameters were set as: the laser power of $6.8 \mathrm{~W}$, the pulse frequency of $50 \mathrm{kHz}$. The groove-type textures with different widths and spacings were prepared. Subsequently, the textured surfaces were successively ground on 2000 mesh sandpaper and polished to remove the surface burr, and then ultrasonically treated in acetone solution for $10 \mathrm{~min}$ to remove the residue.

The thermal oxidation process of samples was carried out in a tubular furnace with air medium. The samples were placed in the center of the tubular furnace and heated at a rate of $5{ }^{\circ} \mathrm{C} / \mathrm{min}$. The parameters of optimum thermal oxidation were $650{ }^{\circ} \mathrm{C}$ for $25 \mathrm{~h}$ 
according to the reference [23]. After the thermal oxidation, the samples were cooled with the furnace.

Table 1. The chemical composition of the TC4 (in wt.\%).

\begin{tabular}{cccccccccc}
\hline Elements & $\mathbf{A l}$ & $\mathbf{V}$ & $\mathbf{F e}$ & $\mathbf{C}$ & $\mathbf{N}$ & $\mathbf{H}$ & $\mathbf{O}$ & Ti & Other Elements \\
\hline TC4 & $5.5-6.8$ & $3.5-4.5$ & 0.30 & 0.10 & 0.05 & 0.015 & 0.2 & Balance & 0.5 \\
\hline
\end{tabular}

The PTFE particles (Particle size: less than $5 \mu \mathrm{m}$ ) were homogeneously dispersed in a mixed epoxy resin adhesive system with curing agent, and then the mixture solution was sprayed onto the surfaces of specimens by a spray gun using $0.2 \mathrm{MPa} \mathrm{N}_{2}$ gas. After the solution evaporation and room temperature curing, the coating with a thickness of 15-20 $\mu \mathrm{m}$ was obtained (The cross-section measured by SEM).

The friction and wear properties of the samples were evaluated by SRV-IV oscillating tester (Optimol, Munich, Germany) under the contact state of ball-on-disk. The corresponding TC4 balls (diameter $10 \mathrm{~mm}$, hardness $350 \pm 15 \mathrm{HV}_{200 \mathrm{~g}}$ ) were driven to slide against the TC4 disk surfaces with a reciprocating distance of $1 \mathrm{~mm}$, and an oscillation frequency of $10 \mathrm{~Hz}$. A normal load of $50 \mathrm{~N}$ and a sliding duration of $30 \mathrm{~min}$ were selected under the room temperature (about $25^{\circ} \mathrm{C}$ ), and the friction coefficient was automatically measured and recorded by the computer. The hardness and roughness of laser textured surfaces were measured by Vickers hardness tester (Shanghai Heng Yi Corporation, Shanghai, China) and surface roughness tester (KEYENCE(China), Shanghai, China), respectively. The wear volume of the sample surface $\left(\Delta V\right.$, unit: $\left.\mathrm{mm}^{3}\right)$ was measured with the VHX-6000 noncontact surface mapping profiler (KEYENCE(China), Shanghai, China). The wear volume is calculated as $\Delta V=A L$, where $\Delta V$ refers to the total wear volume in $\mathrm{mm}^{3}$, and the $A$ is the cross-sectional area in $\mathrm{mm}^{2}$, and the $L$ is reciprocating distance. The friction experiment was carried out three times, and the average value of three tests was given for each sample. The surface morphologies and chemical composition of the samples were characterized by JSM-5600LV scanning electron microscope (SEM, HITACHI, Tokyo, Japan) and energy dispersion spectrometer (EDS, OXFORD INSTRUMENTS, Oxford, UK). The X-ray diffractometer (XRD, PANalytical B.V., Almelo, The Netherlands) was used to analyze the phases of different surfaces, and surface bonding tester (Lanzhou Hua Hui Corporation, Lanzhou, China) was used to test the bonding strength of coating on different surfaces.

\section{Results and Discussion}

\subsection{The Morphologies of Textured Surfaces}

The groove morphologies of the textured surfaces are shown in Figure 1. It can be seen that the surface grooves of the samples are clear and arranged regularly. For the 150 $\mu \mathrm{m}$ fixed width, the texture area density is $27.3 \%, 37.5 \%, 60 \%$, respectively. The roughness of the surface between the grooves was measured to be consistent with the untextured surface, and the effect of LST on the TC4 alloy surface was gauged by Vickers hardness tester. The results indicate that the surface hardness between grooves is $350 \pm 15 \mathrm{HV}_{200 \mathrm{~g}}$, so the influence of laser thermal effect on the hardness of TC4 alloy can be ignored.

The surface micrographs of the thermal oxidation samples were characterized, and the results are shown in Figure 2. It can be seen that the dense oxide layers was formed on the untextured and textured TC4 surface after thermal oxidation treatment, and the state of the oxide layer is consistent for the two surfaces. The oxide layer surface formed about $1.49 \mu \mathrm{m}$ particles, which make the surface rough. The micro-hardness of the oxide layer was $700 \pm 15 \mathrm{HV}_{200 \mathrm{~g}}$, which is twice higher than that of the non-oxidized sample, indicating that thermal oxidation can significantly increase the surface micro-hardness of titanium alloy. Figure 2c shows the XRD curve of the thermal oxidized TC4 surface. It can be seen that rutile $\mathrm{TiO}_{2}$ is formed on the surface after thermal oxidation, while the non-oxidized surface is mainly Ti element and a small amount of Ti compounds. 


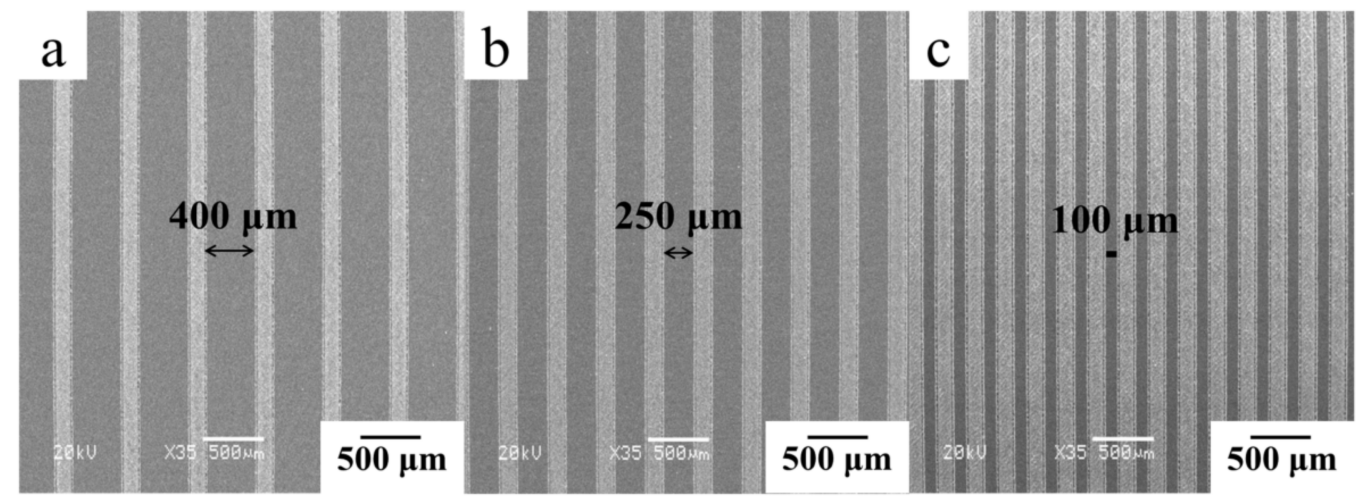

Figure 1. SEM micrographs of the textured surfaces with different spacings: $400 \mu \mathrm{m}(\mathbf{a}), 250 \mu \mathrm{m}(\mathbf{b})$, and $100 \mu \mathrm{m}(\mathbf{c})$.
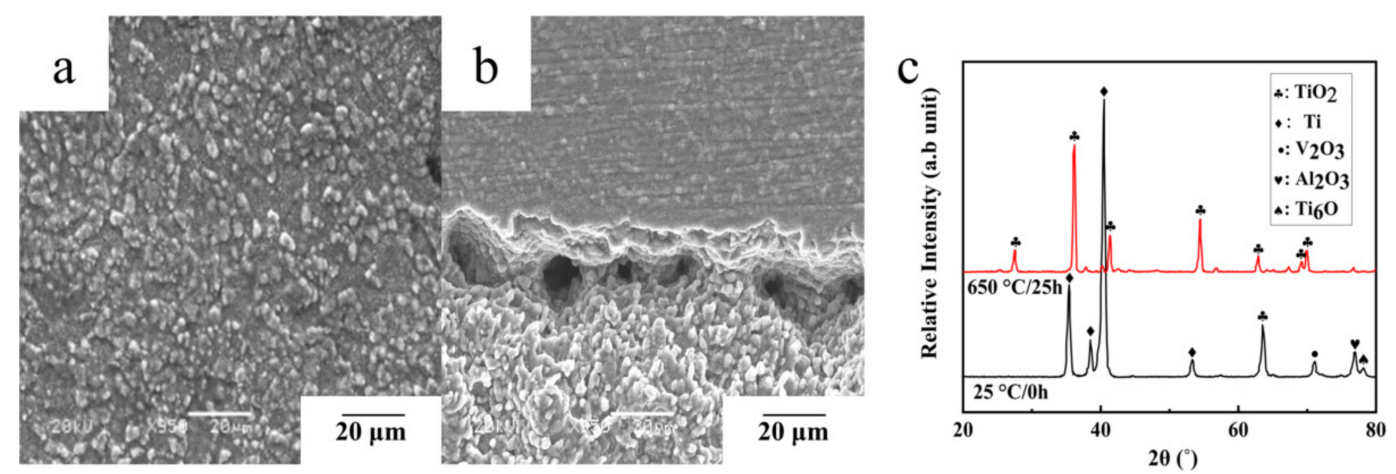

Figure 2. Surface micrographs of untextured (a) and textured (b) samples after thermal oxidation and X-ray diffraction patterns of non-oxidized and oxidized surfaces (c).

The typical cross-section morphology and corresponding EDS mappings of composite lubrication structure are shown in Figure 3. It can be seen that there is an obvious composite layered structure on the TC4 surface. The top layer is a PTFE-based coating with a thickness of about $20 \mu \mathrm{m}$. Meanwhile, for all textured samples, the depth of texture is about $20 \pm 5 \mu \mathrm{m}$. The middle is the thermal oxidation layer with a thickness of about $4 \mu \mathrm{m}$, which formed on the titanium alloy substrate. The PTFE coating is effectively filled into the micro-grooves and closely bonded to the oxide layer.

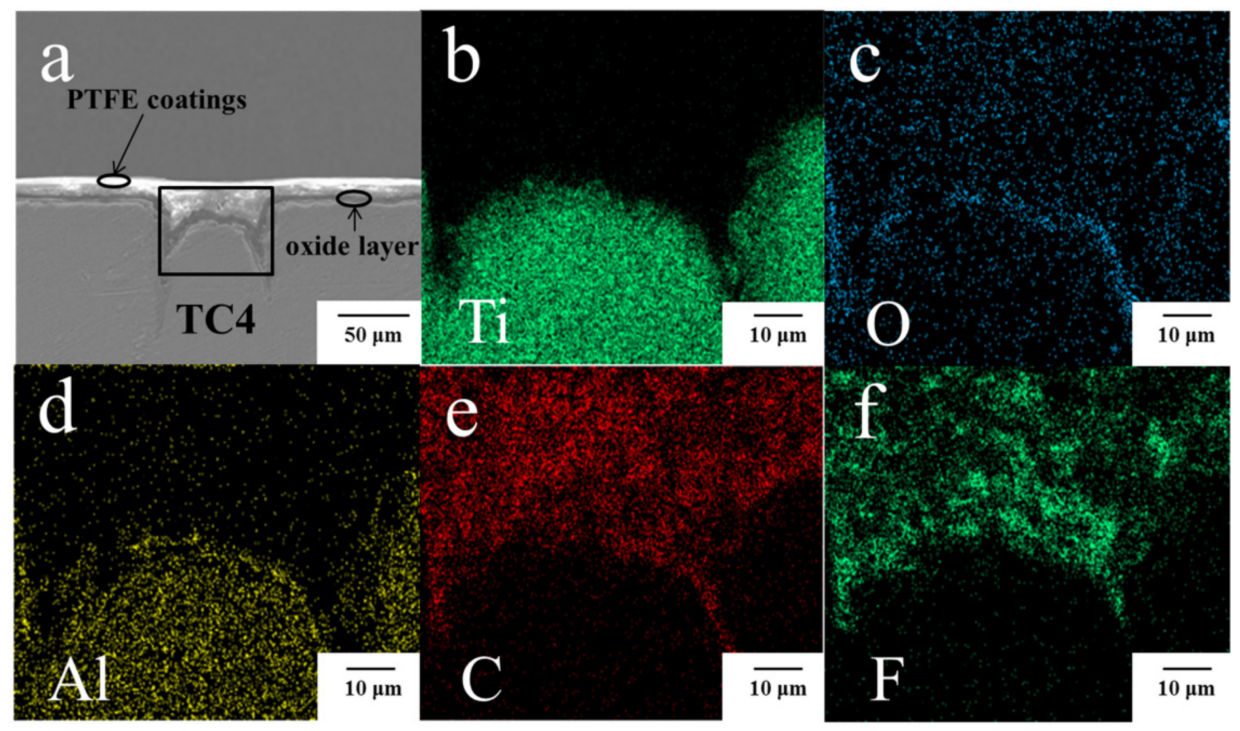

Figure 3. The cross-section (a) and corresponding EDS mappings (b-f) of the composite structure. 
From the results of EDS element distribution of cross-section, there are obvious differences in element distribution for different regions. The substrate is mainly composed of Ti and $\mathrm{Al}$ element, and more $\mathrm{O}$ element is concentrated in the middle layer, indicating the existence of a thermal oxidation layer. The surface layer contains a large amount of $C$ and F elements, which is a PTFE coating. Results show that a composite layered structure is obviously formed.

The adhesion of PTFE coating on the different types of surfaces is compared, and the results are shown in Figure 4. It can be seen that the adhesion of the coating on the thermal oxidation surface is higher than that of on the non-oxidized surface of titanium alloy. The strength is more than five times higher than that of the non-oxidized surface. This shows that the coarsening of the thermal oxidation layer enhances the adhesion of organic coating [24], and the strengthening effect of surface texture further promotes the enhancement of adhesion [25].
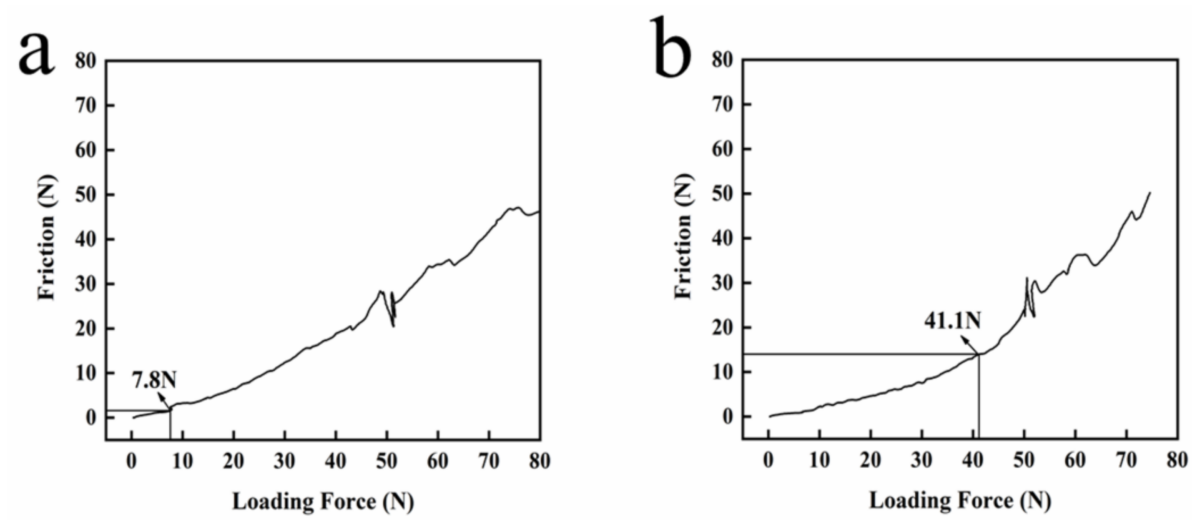

Figure 4. The adhesion force of non-oxidized surface (a) and oxidized surface (b) with PTFE coating.

\subsection{The Influence of Texture Parameters on the Fretting Wear Behaviors of the TC4 Alloy Surface}

The variations of friction coefficient and wear volume of PTFE coating on the textured surfaces with different textured spacings are shown in Figure 5. It can be seen from Figure 5a that the friction coefficient of the untextured surface and low texture density surface increases rapidly at the initial stage, and then fluctuate greatly. The friction coefficient of the surface with $37.5 \%$ density increases sharply after a running of $15 \mathrm{~min}$, indicating that the surface coating is worn out and there is contact between substrates. However, the high-density textured surface $(60 \%)$ shows a lower and more stable friction coefficient with the increases in groove density. Figure $5 b$ provides a summary of the wear volume for the untextured and textured surfaces. It can be seen that the wear volume decreases with the increase of texture density. The results show that the anti-friction and wear resistance of the titanium alloy surface can be significantly improved when the high-density surface texture is combined with the PTFE lubricating coating [26]. Furthermore, under the condition of the same groove widths, the texture spacing has a great impact on the fretting wear behavior of TC4. The reduction of friction coefficient is mainly due to the existence of the PTFE lubricating coating, and the maintenance of the PTFE lubrication transfer film is the key factor. Compared with smooth surfaces, surface texture increases the contact area of coating and significantly improves the bonding force between coating and substrate. The surface texture also can provide effective compensation for the lubrication transfer film on the bearing surface [22]. For the surface with high texture density (smaller texture spacing), more lubricant can be dragged onto the contact surface to effectively form a lubrication transfer film, showing a low and stable friction coefficient.

According to the above results, the effect of texture widths on the fretting wear properties of PTFE coating on the textured surface was further discussed by selecting optimized $100 \mu \mathrm{m}$ texture spacing. The variations of friction coefficient and wear volume for the textured surfaces with different groove widths under $50 \mathrm{~N}$ load are shown in Figure 6. As can be seen from Figure 6a, for the sample with a groove width of $300 \mu \mathrm{m}$, the 
friction coefficient remains relatively stable in the initial stage $(10 \mathrm{~min})$ and then increases rapidly in the second stage with large fluctuations. The average friction coefficient reduces with the decrease of groove widths. Compared with the 80 and $150 \mu \mathrm{m}$ groove width, the sample with the $80 \mu \mathrm{m}$ grooves has the lowest friction coefficient with a very stable trend. Similarly, wear volume decreases with the reduction of groove width. The textured surface with the $80 \mu \mathrm{m}$ grooves has the lowest wear volume of $0.054 \mathrm{~mm}^{3}$, which is approximately six times lower than that of the sample with the $300 \mu \mathrm{m}$ grooves. It can be seen from the results that given the groove spacing, although the $300 \mu \mathrm{m}$ groove width has higher texture area density, it shows adverse tribological properties. It is considered that when the groove spacing is fixed, the smaller the groove width, the more bearing surface under unit amplitude, which is more conducive to the dispersion of compressive stress.
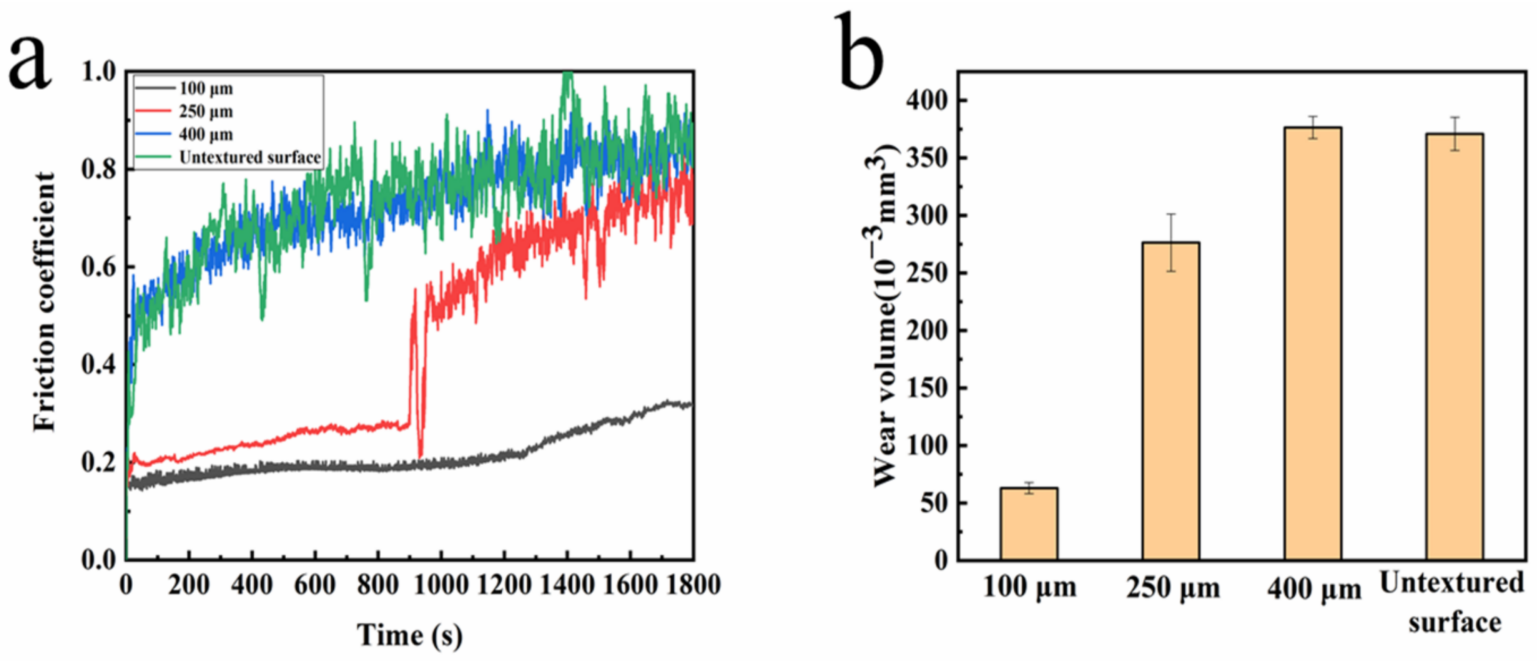

Figure 5. The variations of friction coefficient (a) and wear volume (b) of the textured surfaces with different texture spacings.
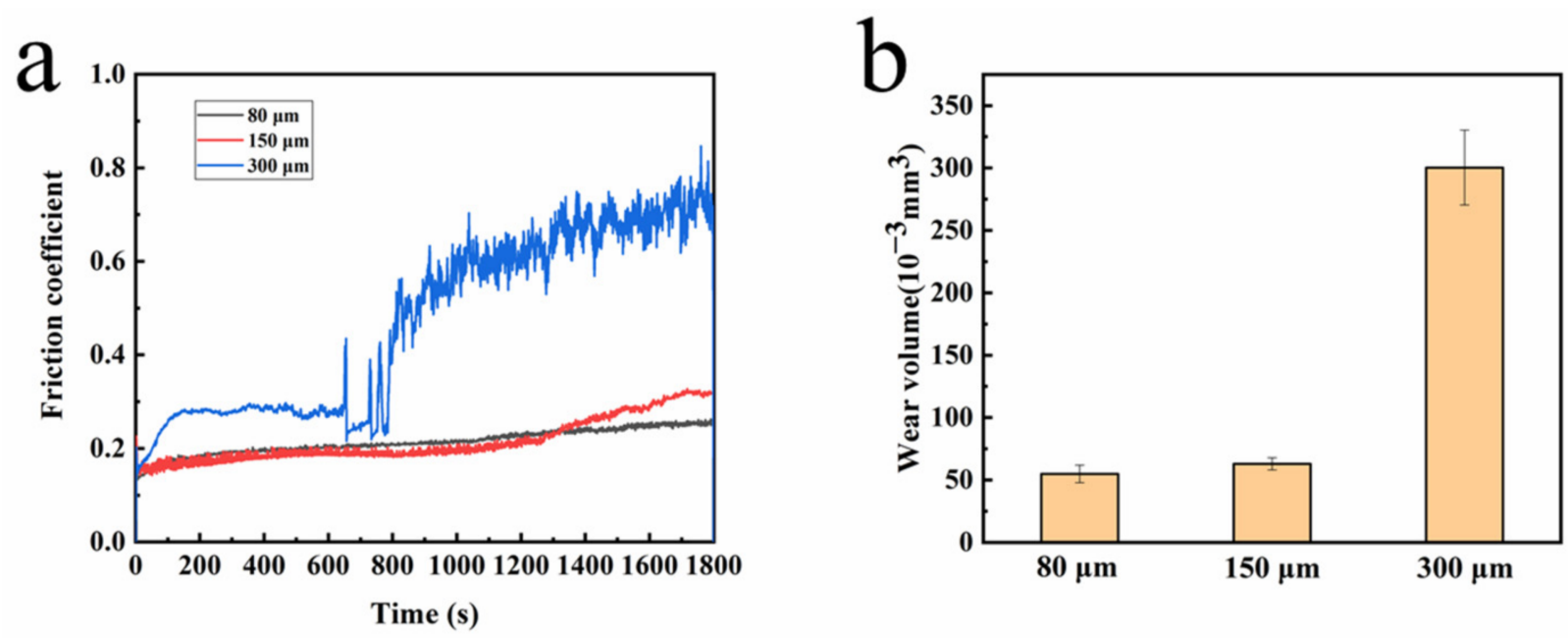

Figure 6. The variations of friction coefficient (a) and wear volume (b) of the texture surfaces with different texture widths.

\subsection{The Influence of the Combination of Thermal Oxide Layer and PTFE-Based Coating on Fretting Wear Behaviors of Textured Surface}

Based on the above experiments, the influence of the thermal oxidation layer on the tribological properties of the PTFE coating of the textured surface was investigated. The texture parameters with a groove width of $80 \mu \mathrm{m}$ and spacing of $100 \mu \mathrm{m}$ were selected for surface texture. Figure 7 illustrated the variation curves of friction coefficient and wear 
volume of the TC4 surfaces with different surface treatments under the normal load of $50 \mathrm{~N}$. All of the surfaces contain a PTFE coating. It can be seen from Figure 7a, the friction coefficient of the untextured surface increases continuously and fluctuates obviously, which demonstrates that the lubricating coating has completely failed, and the wear mechanism is mainly adhesion wear and plastic deformation. When the smooth surface is thermal oxidized, the friction coefficient decreases slightly compared with the non-oxidized surface, but still increases continuously. This is mainly due to the rapid wear of the lubricating coating on the untextured surface, resulting in the contact between the substrates with high friction. However, the thermal oxidation surface plays a certain role in anti-wear owing to the high hardness oxide layer, which avoids direct contact between metal pairs [23]. Therefore, the friction coefficient is lower than that of the non-oxidized surface. Moreover, in the absence of PTFE lubricant, the thermal oxidation surface still shows a high friction coefficient. However, when the smooth surface is textured, the anti-friction and anti-wear properties of the lubricating coating are significantly enhanced, and the average friction coefficient remains about 0.217 with an extremely stable trend.
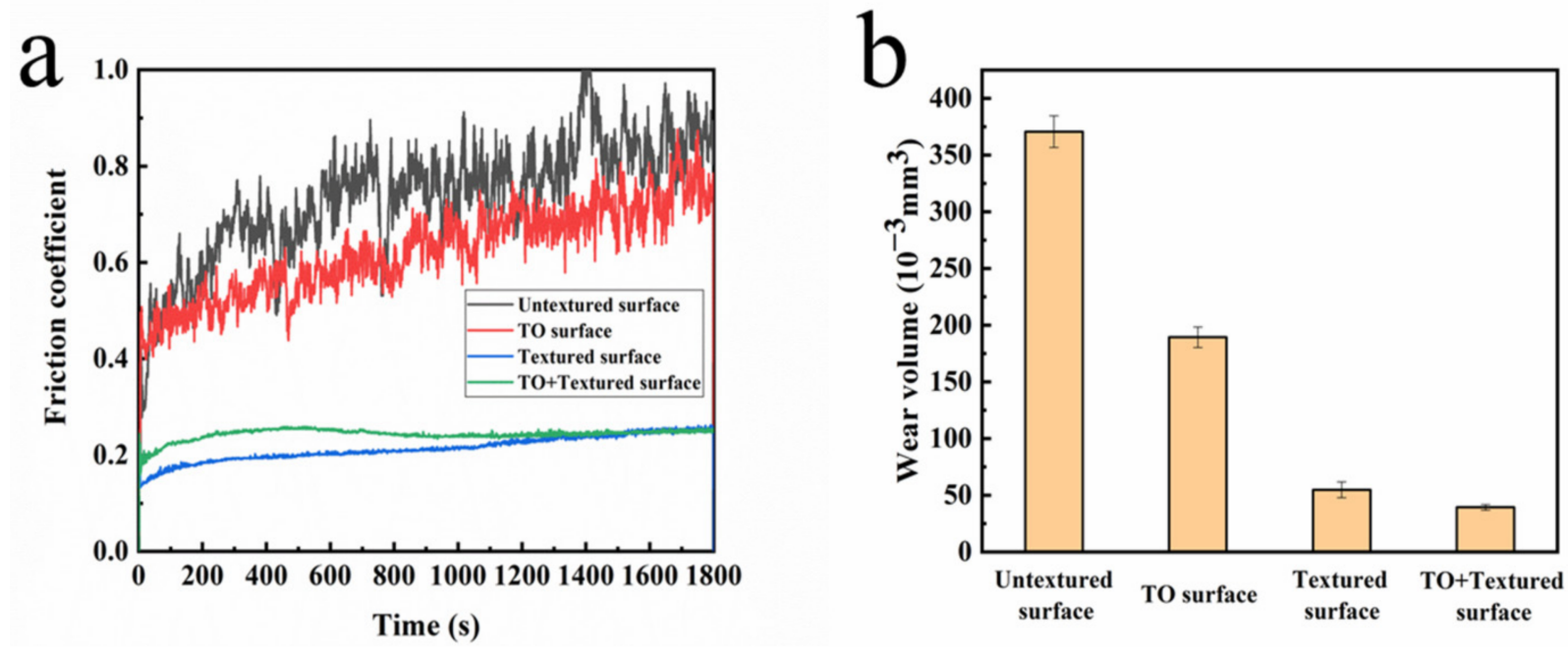

Figure 7. The variations of friction coefficient (a) and wear volume (b) of the different surfaces.

The lubricating coating on the textured surface with the thermal oxidation layer also shows a similar trend. The friction coefficient increases slightly on account of the surface roughness of the thermal oxidation layer, and then the friction coefficient is consistent with the textured surface after a running-in period. In comparison, the untextured surface has the highest wear volume, and the wear volume was significantly reduced after thermal oxidation. However, the wear volume is further reduced when the textured structure is introduced into the surface. When the thermal oxidation layer is combined, the composite structure shows the lowest wear volume, which is $88 \%$ less than that of the untextured surface.

The fretting wear life is investigated for the textured surface and thermal oxidation textured surface, as shown in Figure 8. The results show that the friction coefficient of the coating on the textured surface increases sharply after $2.5 \mathrm{~h}$ of running, while the friction coefficient of the thermal oxidation textured surface remains about $0.2-0.3$ after $9 \mathrm{~h}$ of running without a sharp increase. It can be seen from the worn surface morphology that during the reciprocating movement, the bearing surface between the grooves is gradually worn due to poor wear resistance, and the lubricant in the micro-texture of the textured surface is continuously consumed until the groove is ground flat and the lubricant is lost, which leads to the aggravation of wear. However, for the thermal oxidation textured surface, the worn surface still maintains the existence of grooves structure after $9 \mathrm{~h}$ of running. This shows that the composite lubricating structure has excellent resistance to fretting wear, which is of great significance in engineering applications. 

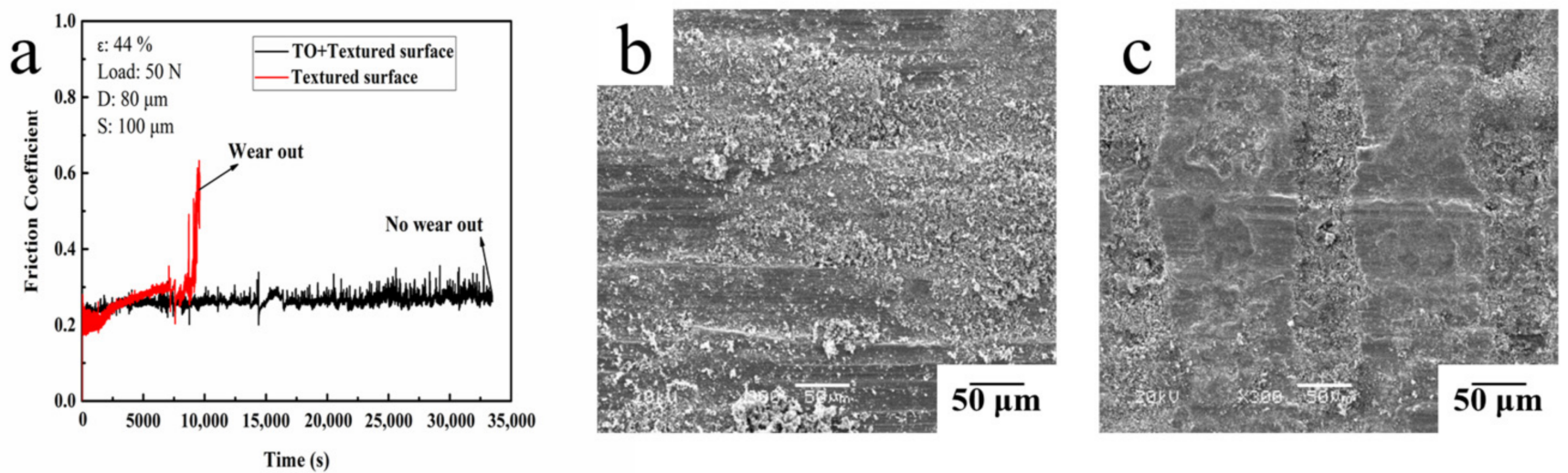

Figure 8. The fretting wear life (a) and SEM micrographs of textured surface (b) and TO+ textured surface (c).

\subsection{Wear Mechanism of the Composite Lubrication Structure}

The wear spot morphologies of several sample surfaces with different treatments were characterized, and the results are shown in Figure 9. The lubricating coating on the untextured surface was completely worn, showing obvious furrow and adhesive wear. The certain wear debris is produced on the wear scar for the thermal oxidation surface, and the oxide layer is worn (Figure $\left.9 b, b^{\prime}\right)$. The area and depth of the wear scar are reduced compared with the untreated surface, indicating that the oxide layer with high hardness plays a role in improving the surface bearing and wear resistance [27]. However, for the textured surface, the lubricant stored in the micro-textures begins to supplement to the edge of the groove after the PTFE coating on the surface is gradually worn, so that the contact surface between the textures shows a smooth wear surface (visible from the enlarged view). Meanwhile, the contact surface between the grooves is also gradually worn, making the groove width narrow. When a thermal oxidation layer is introduced as an intermediate layer on the textured surface, the wear scar area is further reduced. The worn surface is smooth, and the grooves remain intact (Figure $9 \mathrm{~d}, \mathrm{~d}^{\prime}$ ). Compared with the textured surface, the composite structure formed by the introduction of a thermal oxidation layer further improves the wear life of the coating.

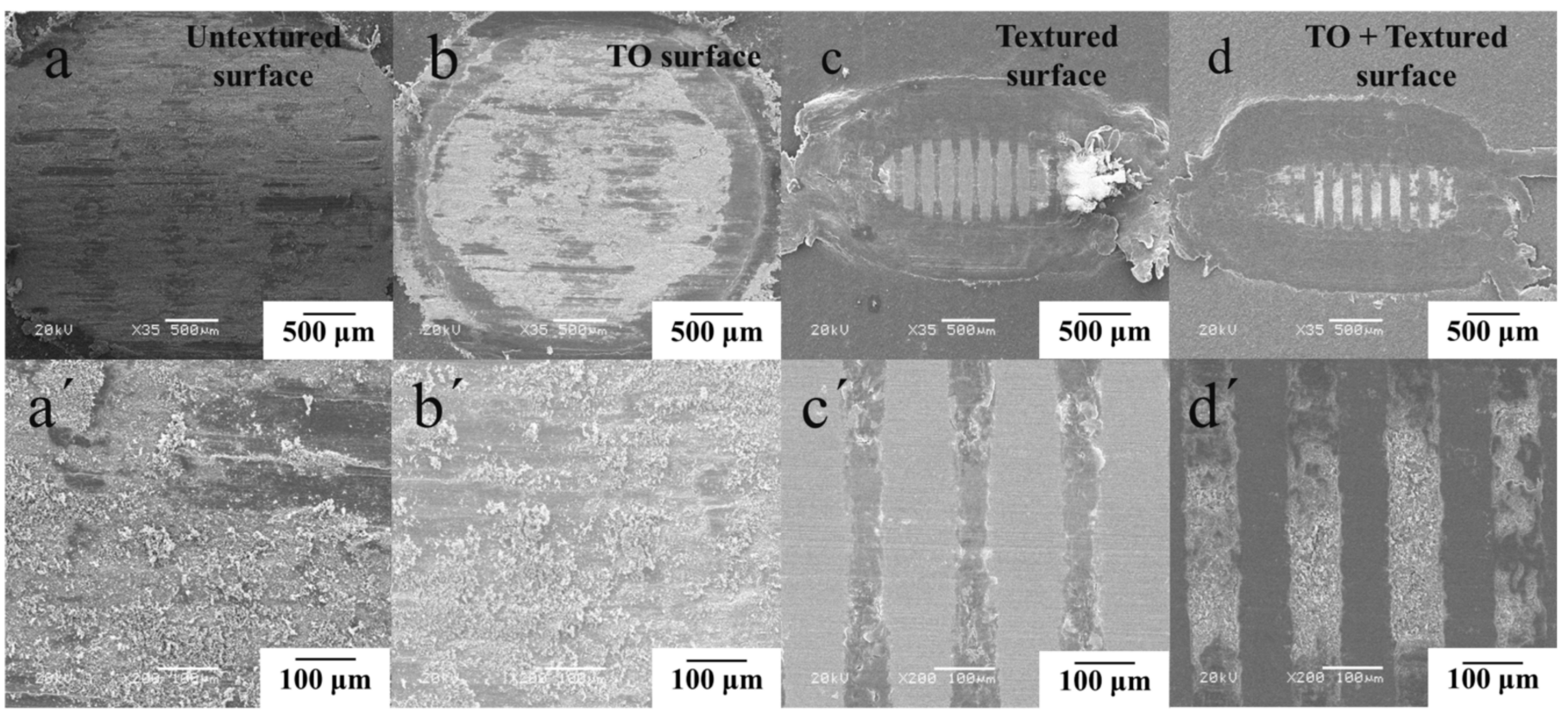

Figure 9. SEM micrographs of the worn surfaces of different surface structures (a-d) and corresponding local worn surfaces $\left(\mathbf{a}^{\prime}-\mathbf{d}^{\prime}\right)$. 
Figure 10 gives the morphologies and element contents of wear scars on the surfaces of four different samples. As shown in Figure 10a,b, for the untextured surface and thermal oxidation surface, the worn surfaces show the existence of titanium alloy matrix elements, and the wear debris exists in the form of $\mathrm{O}$ element. At the same time, there is no F element, which indicates that the lubrication coating has completely failed and the contact between pairing substrates has occurred. However, as shown in Figure 10c, d, there is still a large amount of $\mathrm{F}$ element in the grooves on the textured surface, and there is also a certain amount of F element on the bearing surface between the grooves. It is considered that the solid lubricant filled in the textures is extracted to the edge of the grooves repeatedly during the friction process, which maintains the existence of the lubricating film. By contrast, the contact area of the textured surface with the thermal oxidation is smoother and the distribution of the F element is more uniform under the same running distance, which shows that the thermal oxidation layer and the surface texture play a synergistic role in anti-wear and lubrication.

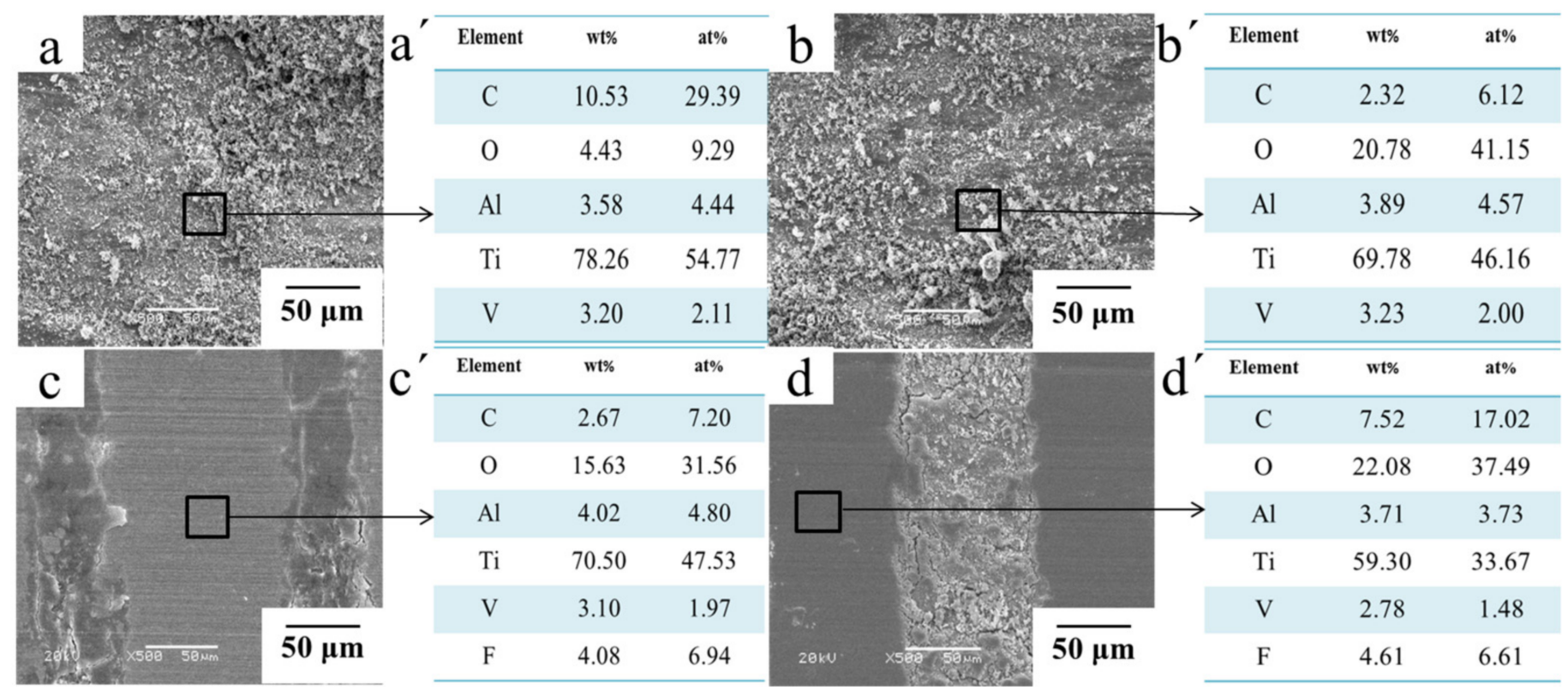

Figure 10. EDS contents of the worn surfaces of untextured surface $\left(\mathbf{a}, \mathbf{a}^{\prime}\right)$, TO surface $\left(\mathbf{b}, \mathbf{b}^{\prime}\right)$, textured surface $\left(\mathbf{c}, \mathbf{c}^{\prime}\right)$, and $\mathrm{TO}+$ textured surface $\left(\mathbf{d}, \mathbf{d}^{\prime}\right)$.

The wear scars of the TC4 balls were also analyzed, and the results were given in Figure 11. When matched with the smooth surface and thermal oxidation surface, respectively, the two balls demonstrate serious wear, and the surface shows obvious furrow and plastic deformation, especially for the ball pairing with a smooth surface. EDS analysis shows that the duality ball of the smooth surface is dominated by the base element of titanium alloy, which indicates that the friction pairs have a substrate contact and the lubrication coating has completely failed. Similarly, the worn surface of the ball pairing with the thermal oxidation surface still shows mainly titanium alloy base elements and contains a very small amount of the F element, indicating that the hard oxide layer alleviates the wear and contributes to the transfer of lubricant. However, when paired with the thermal oxidation textured surface, the ball surface shows a very small wear scar and the obvious PTFE transfer film, which is also confirmed by the existence of more F elements in the distribution of wear scar. The continuous supplement of transfer film for dual surfaces also greatly improves the fretting life of composite lubrication structure.

The experimental results show that the combination of surface texture, thermal oxidation layer and PTFE coating can significantly improve the wear resistance of titanium alloy under fretting friction, and the texture parameter is the key factor to obtain the best wear resistance. This is mainly owing to the multi-layer system of composite lubrication 
structure. On the one hand, the untextured surface shows a serious plow and high friction coefficient when the lubricating coating gradually wears off, and the wear mechanism is mainly plastic deformation, abrasive wear, and delamination wear. On the other hand, compared with untextured surfaces, the main contribution of surface texture to the friction properties is related to the storage of lubricating medium and the effective promotion of lubrication transfer film between pairs [28]. When the width and spacing of grooves are 80 and $100 \mu \mathrm{m}$, respectively, the textured surface shows optimum friction-reduction and anti-wear effect. Under this condition, the textured surface can not only maintain the transfer film of lubricant but also maintain a certain bearing surface without excessive compressive stress on the contact surface. In addition, the combination of surface texture and the thermal oxidation layer further enhances the adhesion of the coating, and the high hardness oxide layer significantly improves the wear resistance of the bearing surface. Therefore, compared with the single textured surface or thermal oxidation layer, the fretting wear life of the PTFE coating is significantly increased by the synergistic effect of surface texture and thermal oxidation layer.

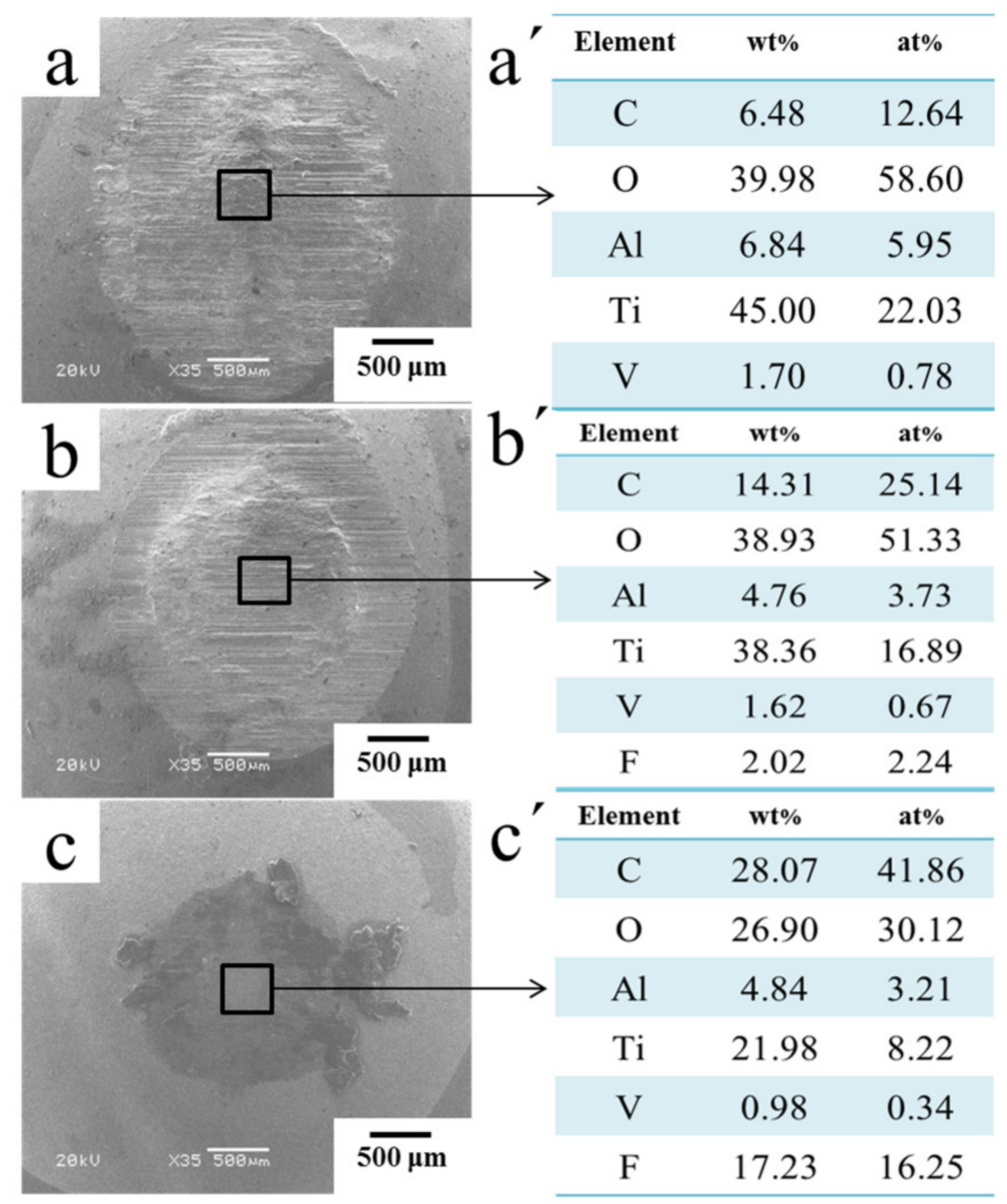

Figure 11. SEM images and EDS contents of worn surfaces of TC4 balls corresponding to untextured surface $\left(\mathbf{a}, \mathbf{a}^{\prime}\right)$, TO surface $\left(\mathbf{b}, \mathbf{b}^{\prime}\right), \mathrm{TO}+$ textured surface $\left(\mathbf{c}, \mathbf{c}^{\prime}\right)$.

\section{Conclusions}

(1) The composite lubricating structure was prepared on the surface of the titanium alloy by combining surface texture, a thermal oxidation layer, and a PTFE lubricating coating. This structure can greatly prolong the wear life under fretting conditions, and the friction coefficient is as low as 0.242 , the wear rate is less than $2.3 \times 10^{-5} \mathrm{~mm}^{3} \cdot \mathrm{N}^{-1} \mathrm{~m}^{-1}$. 
(2) The texture parameters have an important effect on the friction coefficient and wear rate of the composite lubrication structure, the smaller texture spacing and width are more favorable to friction-reducing and anti-wear.

(3) Depending on the role of adhesion enhancement of the surface texture and rough oxide layer to coating, the wear resistance of thermal oxidation layer with high hardness, and the effect of the surface texture on storage and transfer of lubricant, the synergistic influence of the three effects makes the composite structure play the role of self-lubrication and wear resistance.

Author Contributions: Conceptualization, J.S.; Formal analysis, L.H.; Software, H.F.; Writing—original draft, Z.M.; Writing-review \& editing, T.H. All authors have read and agreed to the published version of the manuscript.

Funding: The authors are grateful for the financial support from the National Key Research and Development Program of China (Grant No. 2018YFB2000605), and the Key Research and Development Project of Gansu Province (20YF8GA001).

Institutional Review Board Statement: Not applicable.

Informed Consent Statement: Not applicable.

Data Availability Statement: Data sharing is not applicable to this article.

Conflicts of Interest: The authors declare no conflict of interest.

\section{References}

1. Banerjee, D.; Williams, J.C. Perspectives on Titanium Science and Technology. Acta Mater. 2013, 61, 844-879. [CrossRef]

2. Kumar, V.A.; Gupta, R.K.; Prasad, M.J.N.V.; Murty, S.V.S.N. Recent advances in processing of titanium alloys and titanium aluminides for space applications: A review. J. Mater. Res. 2021, 36, 689-716. [CrossRef]

3. Chamgordani, S.A.; Miresmaeili, R.; Aliofkhazraei, M. Improvement in tribological behavior of commercial pure titanium (CP-Ti) by surface mechanical attrition treatment (SMAT). Tribol. Int. 2018, 119, 744-752. [CrossRef]

4. Sarraf, M.; Ghomi, E.R.; Alipour, S.; Ramakrishna, S.; Sukiman, N.L. A state-of-the-art review of the fabrication and characteristics of titanium and its alloys for biomedical applications. Bio-Design Manuf. 2021, 42, 1-25. [CrossRef] [PubMed]

5. Bai, H.; Zhong, L.; Kang, L.; Liu, J.; Zhuang, W.; Lv, Z.; Xu, Y. A review on wear-resistant coating with high hardness and high toughness on the surface of titanium alloy. J. Alloys Compd. 2021, 882, 160645. [CrossRef]

6. Du, D.; Liu, D.; Ye, Z.; Zhang, X.; Li, F.; Zhou, Z.; Yu, L. Fretting wear and fretting fatigue behaviors of diamond-like carbon and graphite-like carbon films deposited on Ti-6Al-4V alloy. Appl. Surf. Sci. 2014, 313, 462-469. [CrossRef]

7. Li, Z.Y.; Liu, X.L.; Wu, G.Q.; Huang, Z. Fretting Fatigue Behavior of Ti-6Al-4V and Ti-10V-2Fe-3Al Alloys. Met. Mater. Int. 2018, 25, 64-70. [CrossRef]

8. Ye, Z.; Li, J.; Liu, L.; Ma, F.; Zhao, B.; Wang, X. Microstructure and wear performance enhancement of carbon nanotubes reinforced composite coatings fabricated by laser cladding on titanium alloy. Opt. Laser Technol. 2021, 139, 106957. [CrossRef]

9. Rautray, T.R.; Narayanan, R.; Kwon, T.-Y.; Kim, K.-H. Surface modification of titanium and titanium alloys by ion implantation. J. Biomed. Mater. Res. Part B Appl. Biomater. 2010, 93, 581-591. [CrossRef]

10. Chen, X.; Liao, D.; Zhang, D.; Jiang, X.; Zhao, P.; Xu, R. Friction and Wear Behavior of Graphene-Modified Titanium Alloy Micro-arc Oxidation Coatings. Trans. Indian Inst. Met. 2019, 73, 73-80. [CrossRef]

11. Zhang, H.; Dai, Z.; Shi, Y.; Xu, C. Technical note. Effects of Laser Hardening on Fretting Wear Behaviour of Ti Alloy. Surf. Eng. 2001, 17, 518-520. [CrossRef]

12. Kang, J.; Wang, M.; Yue, W.; Fu, Z.; Zhu, L.; She, D.; Wang, C. Tribological Behavior of Titanium Alloy Treated by Nitriding and Surface Texturing Composite Technology. Materials 2019, 12, 301. [CrossRef] [PubMed]

13. Arslan, A.; Masjuki, H.H.; Kalam, A.; Varman, M.; Mufti, R.A.; Mosarof, M.H.; Khuong, L.S.; Quazi, M. Surface Texture Manufacturing Techniques and Tribological Effect of Surface Texturing on Cutting Tool Performance: A Review. Crit. Rev. Solid State Mater. Sci. 2016, 41, 447-481. [CrossRef]

14. Mao, B.; Siddaiah, A.; Liao, Y.; Menezes, P.L. Laser surface texturing and related techniques for enhancing tribological performance of engineering materials: A review. J. Manuf. Process. 2020, 53, 153-173. [CrossRef]

15. Li, X.; Yue, W.; Huang, F.; Kang, J.; Zhu, L.; Tian, B. Tribological behaviour of textured titanium under abrasive wear. Surf. Eng. 2018, 35, 378-386. [CrossRef]

16. Conradi, M.; Kocijan, A.; Klobčar, D.; Podgornik, B. Tribological response of laser-textured Ti6Al4V alloy under dry conditions and lubricated with Hank's solution. Tribol. Int. 2021, 160, 107049. [CrossRef]

17. Dong, H.; Bell, T. Enhanced wear resistance of titanium surfaces by a new thermal oxidation treatment. Wear 2000, 238, 131-137. [CrossRef] 
18. Bailey, R.; Sun, Y. Unlubricated sliding friction and wear characteristics of thermally oxidized commercially pure titanium. Wear 2013, 308, 61-70. [CrossRef]

19. Dalili, N.; Edrisy, A.; Farokhzadeh, K.; Li, J.; Lo, J.; Riahi, A. Improving the wear resistance of Ti-6Al-4V/TiC composites through thermal oxidation (TO). Wear 2010, 269, 590-601. [CrossRef]

20. Jia, Y.; Wan, H.; Chen, L.; Zhou, H.; Chen, J. Effects of nano-LaF 3 on the friction and wear behaviors of PTFE-based bonded solid lubricating coatings under different lubrication conditions. Appl. Surf. Sci. 2016, 382, 73-79. [CrossRef]

21. Yang, Y.; Wang, H.; Ren, J.; Gao, G.; Zhao, G.; Chen, S.; Wang, N.; Wang, J. Multi-environment adaptability of self-lubricating core/shell PTFE@PR composite: Tribological characteristics and transfer mechanism. Tribol. Int. 2020, 154, 106718. [CrossRef]

22. Hu, T.; Hu, L.; Ding, Q. The effect of laser surface texturing on the tribological behavior of Ti-6Al-4V. Proc. Inst. Mech. Eng. Part J: J. Eng. Tribol. 2012, 226, 854-863. [CrossRef]

23. Sun, Q.; Hu, T.; Fan, H.; Zhang, Y.; Hu, L. Thermal oxidation behavior and tribological properties of textured TC4 surface: Influence of thermal oxidation temperature and time. Tribol. Int. 2016, 94, 479-489. [CrossRef]

24. Zhang, P.; Zou, X.; Zhang, S.; Xia, C.; Liang, C.; Liu, N.; Wang, H. Improve the binding force of PEEK coating with Mg surface by femtosecond lasers induced micro/nanostructures. J. Mater. Sci. 2021, 56, 13313-13322. [CrossRef]

25. Rosenkranz, A.; Costa, H.L.; Baykara, M.Z.; Martini, A. Synergetic effects of surface texturing and solid lubricants to tailor friction and wear-A review. Tribol. Int. 2020, 155, 106792. [CrossRef]

26. Sun, Q.; Hu, T.; Fan, H.; Zhang, Y.; Hu, L. Dry sliding wear behavior of TC11 alloy at $500^{\circ} \mathrm{C}$ : Influence of laser surface texturing. Tribol. Int. 2015, 92, 136-145. [CrossRef]

27. Mao, Y.; Wang, L.; Chen, K.; Wang, S.; Cui, X. Tribo-layer and its role in dry sliding wear of Ti-6Al-4V alloy. Wear 2013, 297, 1032-1039. [CrossRef]

28. He, D.; Zheng, S.; Pu, J.; Zhang, G.; Hu, L. Improving tribological properties of titanium alloys by combining laser surface texturing and diamond-like carbon film. Tribol. Int. 2015, 82, 20-27. [CrossRef] 